\title{
Novos rumos para o \\ Ensino Médio Noturno \\ - como e por que fazer?
}

Lia Rodrigues Gonçalves

Sara Rozinda Martins Moura Sá dos Passos

Álvaro Mariano dos Passos

\section{Resumo}

Este artigo se refere à necessidade de se propiciar um canal de reflexão, discussão e ação junto aos professores que atuam no ensino médio noturno e, conseqüentemente, promover a melhoria de um ensino, que há muito tempo é apenas um simulacro. Para tal, apresentamos alguns resultados da investigação iniciada em dezembro de 2003 no Colégio Estadual Presidente Kennedy, em Belford Roxo Baixada Fluminense/RJ, entre alunos e professores, equipe técnica e gestores. Queremos evidenciar a complexidade do processo de mudança, pois representa um desafio. Não se muda por decreto ou querência deste ou daquele grupo. Mudança é processo e sendo assim, exige um árduo trabalho de desconstrução e reconstrução a que os atores desse processo terão que se dedicar com competência, contínua e pacientemente. Não se trata apenas de mudar, mas de inovar.

Palavras-chave: Reflexão. Desconstrução. Reconstrução. Comprometimento.

\section{Abstract \\ New avenues for evening high school classes - Why and how?}

This article is about the need to provide a channel of reflexion, discussion, and action with high school evening class teachers, and consequently, promote a teaching improvement. For the past few years, teaching evening classes has been only a simulacrum. For such, we present some results of a reseach iniciated in December, 2003, at the Colégio Estadual Presidente Kennedy, in the city of Berlford Roxo, State of Rio de Janeiro. The research was done among teachers, students, staff, and directors. We want to make evident the complexity of any changing process. We do not change by decree or desire of this or that group. Changing is a process and, therefore, requires 
a strong work of deconstruction and reconstruction to which the actors of such process will have to dedicate themselves with competence and patience. It is not only about changing, but about innovating.

Keywords: Reflection. Reconstruction. Commitment.

\section{RESUMEN}

\section{Nuevos rumbos para la Enseñanza Media Nocturna - ¿̇cómo y porqué hacerla?}

Este artículo se refiere a la necesidad de propiciarse un canal de reflexión, discusión y acción junto a los profesores que actúan en la enseñanza media nocturna $y$, consecuentemente, promover la mejora de una enseñanza, que hace mucho tiempo es apenas un simulacro. Para tal, presentamos algunos resultados de la investigación iniciada en diciembre de 2003 en el Colegio Estadual Presidente Kennedy, en la ciudad de Belford Roxo, Estado do Rio de Janeiro, entre alumnos y profesores, equipo técnico y gestores. Queremos evidenciar la complejidad del proceso de cambios, pues representa un desafío. No se cambia por decreto o deseo de este o de aquel grupo. El cambio es un proceso y, por eso, exige un arduo trabajo de destrucción y reconstrucción al cual los actores de ese proceso tendrán que dedicarse con competencia, continua y pacientemente. No se trata apenas de cambiar, sino de innovar.

Palabras clave: Reflexión. Destrucción. Reconstrucción. Compromiso.

\section{Ponto de partida}

O sonho idealizado dos profissionais da educação é que a escola seja um local de incentivo, de desafios, de construção do conhecimento, de transformações. Um lugar onde haja o debate acerca das questões sociais e culturais; a eleição conjunta e refletida dos princípios e valores que devem ser vivenciados; a formulação e implementação de um projeto pedagógico viável para a comunidade escolar; obviamente, além dos conteúdos sistematizados. Um lugar que contemple a leitura de mundo e a discussão, que possibilite a construção de relações de emancipação e autonomia, de criação e recriação do trabalho educativo, levando ao desenvolvimento professores e alunos, e conseqüentemente a valorização e ao reconhecimento do trabalho docente. Enfim, um local de ensino e aprendizagem.

Deste sonho apenas algumas escolas públicas estaduais diurnas são contempladas, porque a realidade dos cursos noturnos é diametralmente oposta àquilo que idealizamos. Por isso, não é difícil constatar que em meio a tudo que se diz, se lê e se escreve, a propósito de políticas educacionais a serem deflagradas ou fortalecidas, o ensino médio, principalmente, o que existe no curso noturno, até o presente momento, é o grande ausente no conjunto de medidas concretas acenadas para a melhoria do sistema de educação básica.

De um modo geral, o cotidiano do ensino noturno apresenta uma característica singular, pois recebe um alunado esgotado, que na sua grande maioria, chega à escola após uma jornada de trabalho. Um alunado que já chega reprovado pelo cansaço, que se evade e desiste da escola, porque o que aprende na sala de aula pouco tem a ver com o mundo do trabalho. Neste contexto, a realidade do Colégio Estadual Presidente Kennedy - CEPK, locali- 
zado em Belford Roxo - Baixada Fluminense -, não é diferente de outras unidades estaduais de ensino que atuam à noite.

Objetivando pesquisar novos rumos para o ensino médio noturno, partimos da evidência que, em qualquer sala de aula do noturno são claramente observados os baixos índices de produtividade; os altos índices de desistência; a freqüência irregular às aulas. Embora os cursos diurno e noturno tenham características pedagógicas diferentes, eles têm a Proposta Curricular organizada e efetivada como se fossem idênticos. Esta evidência exige uma profunda reflexão: o ensino noturno deve ser oferecido de forma idêntica ao diurno? Até que ponto a escola pública pode avaliar para criar um aprendizado coletivo e uma dinâmica de mudança? De que forma professores e alunos podem criar um aprendizado coletivo?

Partindo dessas considerações, decidimos os sujeitos da pesquisa: professores e alunos do curso noturno do CEPK, uma vez que para se desenhar os novos rumos para o ensino médio noturno a participação desses dois elementos é fundamental. Mergulhamos, então, na prática cotidiana escolar através de encontros, conversas informais, levantamento de informações. Sendo assim, a elaboração dos questionários compartilhou-se entre as autoras, a equipe técnico-pedagógica, o conseIho pedagógico e a direção do colégio, que na versão final, apresenta questionários distintos para professores e alunos. Foram respondentes: 25 professores (dos 40 docentes do curso noturno) e 250 alunos (dos 911 alunos do ensino médio noturno).

Procuramos concentrar o problema em fatores que respondessem aos seguintes questionamentos: $\bigcirc$ Ensino Médio noturno cum- pre as funções para que foi criado? $\bigcirc$ curso noturno atende às necessidades da clientela de faixa etária a partir dos 15 anos? A metodologia utilizada durante as aulas é adequada ao ensino noturno? Quais as dificuldades de freqüência, permanência e aproveitamento dos alunos no curso noturno?

Nesta etapa inicial da investigação, os objetivos foram: a) Por amostragem simples, levantar e analisar as características dos sujeitos da pesquisa através das respostas dadas aos questionários; b) Levantar questões de discussão sobre o "como" e o "porquê" o ensino noturno pode ser modificado, minimizando as questões que concorrem para o reduzido sucesso de professores e alunos. E este é o motivo deste artigo, trazer a público uma reflexão acerca dos resultados obtidos.

\section{A fundamentação teórica}

Em qualquer projeto pedagógico observa-se a citação sobre a necessidade de práticas educativas pautadas na realidade social do aluno. Entretanto, o que significa "realidade social do aluno"? Qual a conotação dessa expressão? Que representações e imagens se formam para o termo "realidade"? Entendemos que realidade é o que vemos, contudo precisamos aprender a vê-la. Logo, não objetivamos apenas descrever as condições de vida dos alunos do noturno e inferir que isso representa a realidade existencial deles. Foi necessário compreender as atitudes desses alunos em face dessas condições. Conhecer suas necessidades, seus desejos e de suas transações representativas e imaginárias, isto é, "ver" a realidade social e tentar encontrar meios para trabalhá-la. Caso contrário, as ações e práticas educativas reduzem-se a uma farsa onde professores e alunos, cada 
qual em seu mundo, fingem que trocam informações, conhecimentos e afetos. Portanto, não basta levantar a realidade social de uma escola, não basta levantar os indicadores de matrícula, renda familiar, idade, sexo, moradia. Mapear esses elementos é extremamente importante para um contato inicial com essa realidade, entretanto eles não dizem tudo. É preciso, sobretudo, aprender a vê-la e, reconhecê-la como historicamente determinada, para tentar compreender o sentido que esta realidade social tem para os professores e alunos do noturno: quais as condições difíceis que alunos e professores enfrentam em seu cotidiano? Que mecanismos recorrem para superar essas dificuldades?

No Brasil, a LDB - Lei 9394/96, o artigo 26 preconiza que "os currículos do ensino médio devem ter uma base nacional comum, a ser complementada, em cada sistema de ensino e estabelecimento escolar, por uma parte diversificada, exigida pelas características regionais e locais da sociedade, da cultura, da economia e da clientela." E o artigo 36, na Seção I, destaca as diretrizes do ensino médio. Um currículo que dá acesso ao conhecimento tecnológico e científico, às diferentes formas de linguagem e ao exercício da cidadania. Cabe, aqui, destacarmos algumas idéias apresentadas em Pacheco (2003), onde comunidade não é uma questão de espaço, mas um corpo de tendências com vistas à ação e ao sentido e, currículo é todo um conjunto de experiências, diretas ou indiretas, direcionadas para a revelação das capacidades do indivíduo, experiência esta que cada ser humano deve possuir. Sendo assim, o currículo deve ser construído de forma relacional e por meio de alianças efetivas, além de fazer parte do processo de construção da identidade coletiva. Currículo é o instrumento adequado de regulação não só para a formulação dos objetivos de aprendizagem, que se encontram nas diversas formas de seleção e organização do conhecimento oficial, bem como para o estabelecimento de critérios de controle (PACHECO, 2003). Neste contexto, é importante ressaltar que a unificação formal do currículo não assegura a equalização das oportunidades educacionais, pois aulas no período diurno e aulas no período noturno, após uma jornada de trabaIho, configuram situações bem diferentes.

Muitas pesquisas sobre o papel da escola como transmissora de conhecimentos têm sido realizadas, chegando a diferentes conclusões, entre tantas, destacamos os estudos de Bourdieu e Passaron sobre a teoria da violência simbólica - a arbitrariedade da ação pedagógica ao impor conteúdos previamente selecionados. Em contraposição ao engessamento produzido pelo currículo imposto, Pacheco (2003) reforça o argumento da construção da autonomia curricular dentro da própria escola, oportunizando-se situações curriculares pouco estruturadas que possam permitir aos alunos refletirem sobre suas experiências de vida, através de projetos flexíveis, fundamentados nos princípios de uma educação democrática.

Lembramos que as reformas educacionais não brotam do interior da escola, nem saem exclusivamente do poder estatal, mas devem ser geradas e geridas no envolvimento dos atores em questão: gestores, professores e alunos. Dentro deste novo desenho para ensino e aprendizagem, Schön (2000) argumenta sobre o "processo de reflexãona-ação", que é a capacidade de refletir, estimulada pela interação professor-aluno em 
diferentes situações práticas, onde a formação profissional não é trabalhada de forma cartesiana, mas na relação reflexiva de teoria e prática. Fundamentadas nesse argumento, questionamos: por que os conteúdos curriculares do ensino médio estão determinados pelos livros didáticos, vestibulares e concursos? Por que não produzir a construção de conhecimentos de acordo com a realidade social, necessidade e expectativas do aluno enquanto pessoa?

Em todo este contexto, observa-se que há várias décadas a escola vem transformando as desigualdades sociais e culturais em desigualdades de resultados escolares, devido à sua "indiferença pelas diferenças". Atualmente, novas ferramentas estão sendo utilizadas para demonstrar que o fracasso escolar não é uma fatalidade, aí estão: a pedagogia de suporte, a pedagogia diferenciada, a individualização dos percursos de formação, o ensino por ciclos, os estudos dirigidos e módulos no ensino médio, entre outras (PERRENOUD, 2001). Considerar as diferenças é oportunizar aos alunos o acesso e a apropriação de uma cultura básica comum, através de situações eficientes de aprendizagem, sem que $O$ aluno tenha que renunciar à diversificação. (PERRENOUD, 2000).

Na busca de soluções para os muitos problemas, os sistemas educacionais encontraram algumas respostas no ensino modular, dentro deste contexto, os cursos técnicos do Estado do Rio estão organizados. Gimeno Sacristán (2000) oferece uma interessante observação sobre o ensino modular, que apresenta maior coerência entre os conteúdos com determinados núcleos ordenadores do saber, como também, permite relacionar os conteúdos com atividades práticas, habilidades diversas que não costumam depender de conteúdos específicos; favorece a ordenação do trabalho dentro da classe e na escola em grupos de diferente nível e ritmo de progresso, recurso fundamental para facilitar o tratamento da diversidade e diferenças entre alunos e, assegura o significado de certos objetivos e parcelas curriculares, ocasionando a programação da avaliação que o professor realiza do aluno, o diagnóstico do progresso do mesmo e a regulação de sua promoção dentro do sistema escola. Além de, obviamente, facilitar a motivação do aluno.

Na escola urge que haja mudanças, todavia elas não podem ser analisadas na base da opinião pessoal e do mero consenso, mas na base da investigação e avaliação das experiências. Urge que a comunidade escolar comprometa-se com a inovação que se faz necessária. Sobretudo, compete aos professores um trabalho de educação permanente, para mudar a concepção, mudar a postura, para então mudar a prática. $\bigcirc$ trabalho inicial a ser feito é motivar os professores a montar grupos de estudo para se conceber uma prática pedagógica que atenda aos interesses e necessidades dos alunos da noite. Isso é desenvolvimento profissional do professor (RODRIGUES, 1987).

\section{Revelando resultados}

$O$ mergulho na realidade educacional do CEPK possibilitou-nos confrontar com um leque de desafios. Em qualquer segmento, seja de administradores, de orientadores, de professores ou de alunos, há um rol enorme de queixas e angústias. Conseqüência das reformas educacionais que prometem, mas que não acontecem. Aliado à inconsistência e às contradições do sistema público de ensino, existe uma grave crise de valores re- 
ferenciais que perpassa pela humanidade. Em outras palavras, os problemas existem e não são resolvidos, porém ajeitados, transferidos, mascarados.

Verificamos que $60 \%$ dos professores-respondentes são jovens profissionais que possuem até 10 anos de carreira. E que são unânimes em afirmar positivamente sobre a importância de se conhecer a realidade, as necessidades e os interesses de seus alunos, visando a um ensino de qualidade. Bem como, sobre a possibilidade e importância de se construir um trabalho coletivo entre professores e alunos, visando a um projeto curricular que vincule conteúdos relevantes à realidade e às expectativas dos alunos. Neste contexto, percebemos que os docentes estão equipados com um discurso, mas que não corresponde a um avanço na prática. Observem que, quando foram perguntados sobre o motivo que impede o professor de oferecer aulas desafiadoras, levando os alunos à construção do conhecimento, 40\% responderam que o impedimento está na falta de horário para o planejamento; 28\% em outros, a saber: no somatório dos seis motivos apresentados, no número de aulas e no número de alunos em sala; $20 \%$ na falta de interesse do aluno; $12 \%$ na falta de motivação docente.

Para caracterizar a escola através de sua clientela, se faz necessário um olhar sobre o número de alunos matriculados e, um fato logo se destaca: a existência de um maior número de alunos nas séries iniciais do Ensino Médio. Todavia, a necessidade de combinar trabalho e estudo, acusa número bem diferente entre matrícula inicial e final, o que justifica o alto índice de reprovações e dependência na primeira série e o alto índice de evasão ao longo das demais séries.
Contrariando alguns mitos sobre as características dos alunos do ensino noturno, observamos que $52 \%$ dos alunos-respondentes são do sexo feminino, contra $48 \%$ do sexo masculino. Fator interessante é que o ensino médio noturno está sendo freqüentado por jovens, pois $48 \%$ dos alunos possuem entre 15 e 19 anos. Outro ponto que também sofreu transformação foi sobre a naturalidade dos alunos, a Baixada Fluminense era conhecida por ser o reduto dos emigrantes do Nordeste, fato que justificava uma população de baixa renda. Pela investigação, observamos que 68\% dos alunos já são nascidos no próprio Estado do Rio de Janeiro. Quanto ao perfil ocupacional do grupo verificamos que $43 \%$ desenvolvem trabalho assalariado, mas que $44 \%$ estão desempregados e que 14\% nunca trabalharam. As atividades profissionais desempenhadas relacionam-se ao setor terciário, são: balconistas, atendentes, secretárias, manicures, pedreiros, mecânicos, empregadas domésticas (babás), motoristas, funcionários públicos (limpeza). A maioria dos empregos é mera ocupação, que não exige qualificação específica, quase sempre em turno de oito horas. Esses subempregos são características do mercado de trabalho da região, para aqueles que têm problemas de freqüência, permanência e aproveitamento na escola. Sobre a convivência em família, levantamos que $67 \%$ desses jovens vivem com suas famílias; $22 \%$ já constituíram família e apenas 3\% vivem sozinhos. Quanto o local da residência do aluno, verificamos que $80 \%$ dos alunos residem no centro de Belford Roxo ou em bairros próximos ao que está localizado o colégio, contrariando o argumento de que o aluno do Kennedy era de bairro distante ou de outro município. O domicílio de 76\% dos alunos é próprio. 
De acordo com os professores, $56 \%$ dos alunos do curso noturno procuram no Kennedy o certificado que garantirá o emprego e/ou melhorias salariais; $40 \%$ procuram o conhecimento, que possibilitará outras oportunidades individuais, coletivas e profissionais e, $4 \%$ vêm em busca da ilusão de que a escola promove ascensão social.

Verificamos que apesar das afirmativas docentes sobre a importância de se conhecer a realidade de seus alunos, na verdade poucos realmente direcionam sua prática docente para este conhecimento, pois muitos professores ainda não perceberam que os objetivos dos seus alunos modificaramse. Observamos que $74 \%$ dos alunos afirmaram que estão em busca do conhecimento que possibilitará oportunidades individuais, coletivas e profissionais. $O$ aluno mudou, se antes ele queria apenas um diploma, hoje, ele quer o conhecimento que lhes dê acesso à universidade ou à carreira militar. Dos 250 alunos-respondentes, 185 já perceberam a importância, pessoal e profissional, de se ter acesso ao conhecimento científico necessário para a organização e desenvolvimento autônomo. Acreditam os alunos que, se continuarem estudando, poderão alcançar um futuro melhor. Até que ponto os professores conhecem a realidade de seus alunos? Conhecer não para favorecê-los, nem para prejudicá-los. Conhecer essa realidade para promover a tradução do conhecimento, levando os alunos à construção e aplicação do conhecimento, um conhecimento que vai servir para que esses alunos possam modificar sua realidade.

Perguntados sobre a diferença básica entre o aluno do diurno e o aluno do noturno, 56\% dos professores acreditam que a diferença está no desgaste físico e mental do aluno do noturno. E por mais incrível que possa parecer, $8 \%$ desses docentes não percebem nenhuma diferença. Sobre a importância do componente curricular que o professor ensina, 56\% responderam que sim, que a disciplina prepara os alunos para atuarem na sua vida de jovem/adulto; $44 \%$ não têm esta certeza.

Com relação às informações transmitidas em sala de aula, 56\% dos professores percebem que os componentes curriculares que ensinam são importantes para preparar os alunos a atuarem na vida de jovem/adulto. Contudo, apenas $42 \%$ consideram as informações trabalhadas em sala de aula como importantes. Nesta questão, fica bem evidente que o que é importante para o professor, não é importante para muitos alunos, isto é, não atende as expectativas da grande maioria. E não atende porque, na visão do aluno, o academicismo dos componentes curriculares é muito difícil e, com pouca aplicabilidade no mundo do trabalho que ele enfrenta fora dos muros escolares.

Considerando que uma escola precisa atender as expectativas de seus alunos, professores e alunos manifestaram seus pontos de vista sobre o processo ensino-aprendizagem. Igualmente, $48 \%$ dos professores e dos alunos estão ensinando/aprendendo a ser uma pessoa pensante e atuante. $72 \%$ dos alunos acreditam que a escola é responsável pelos resultados que produz, através do trabalho realizado pelos seus professores em sala de aula (aulas, tarefas e avaliações), sendo assim, para esses alunos o Kennedy investe no talento do aluno. Para os professores, perguntamos o que ele está fazendo para investir no talento dos seus alunos? 44\% estão interagindo com os alunos, procurando saber deles as suas 
realidades de vida, suas necessidades, suas dificuldades, para melhor orientá-los; 32\% estão buscando capacitação para que possam desenvolver competências e habilidades nos alunos, promovendo uma aprendizagem mais eficaz e eficiente; $20 \%$ estão investindo no aluno que quer aprender e, os professores estão aqui para ensinar e, 4\% optaram por outras respostas. A partir do fato de que o ensino diurno (manhã e tarde) é realizado em 30 h semanais, seis h/a diárias, para um aluno que, geralmente, não trabalha, $80 \%$ dos professores e $55 \%$ dos alunos consideram que o curso noturno deve ser adequado aos alunos que já cumpriram um dia de trabalho, diferente do aluno do diurno que, geralmente, não trabalha.

As questões comentadas no parágrafo anterior estão interligadas e apresentam algumas contradições tanto entre professores como alunos. Percebemos que nos dois grupos há uma satisfação com a escola no geral, mas que no particular há muitos hábitos enraizados e, neste contexto, a tomada de consciência para a mudança é tarefa complexa. Estar satisfeito com o atendimento às necessidades de sua clientela é uma das avaliações que a escola pública sofre, através do cumprimento do seu projeto pedagógico. Mas, não basta estar no papel, o projeto da escola precisa ser praticado em cada sala de aula.

Teoricamente sabemos que as funções docentes estão em constante mudança, cabe a cada participante assumir posição crítica através do conhecimento da realidade, a fim de elucidar a natureza dessa mudança. Na prática, o que ocorre é a reclamação constante por parte dos professores sobre a mudança ocorrida na clientela que freqüenta o ensino noturno.
Observamos que se o comportamento da clientela mudou, deve mudar também a atuação docente. Como? Por quê? Com que intenções? São questionamentos que o professor precisa fazer para se tornar mais consciente da sua função. Para que possa assumir um posicionamento mais crítico e organizado sobre a realidade com a qual trabalha; para servir aos reais interesses, anseios, motivações dessa clientela que pertence ao mundo do trabalho.

Mudou a clientela do ensino médio noturno, mudou também a clientela dos cursos subseqüentes. Mudou porque a sociedade brasileira também mudou. Não podemos esquecer que a escola e a prática educativa que nela ocorre, faz parte de uma prática social mais ampla, que precisa ser pensada, assimilada criticamente, para então ser discutida, para que a partir daí se possa elaborar, em nível de prática educativa, o que se deseja transformar. Denunciar, apenas, que essa clientela mudou e que não é possível trabalhar com ela em função das suas múltiplas carências, é ficar numa posição cômoda de simples denúncia, sem agir sobre ela.

Ainda procurando levantar a opinião de professores e alunos, perguntamos se a metodologia empregada nas aulas do curso diurno deveria ser a mesma a ser empregada no curso noturno? 68\% dos professores responderam que não, as aulas do noturno devem ser o menos teórica possível, onde os conceitos devem ter aplicação na vida prática e 60\% dos alunos responderam que sim, o aluno do noturno deve ter o mesmo tratamento do aluno do diurno, com aulas teóricas e práticas. Logo, $60 \%$ de ambos os grupos percebem que as aulas do diurno e as do noturno, após uma 
jornada de trabalho, configuram duas situações bem diversas. $\bigcirc$ professor percebe que $\mathrm{o}$ ensino precisa ter aplicabilidade. $\bigcirc$ aluno não quer um ensino mais "resumido" ou aprendizagens facilitadas, ele quer conhecimento teórico e prático, pois, ele precisa continuar trabalhando e quer chegar à universidade ou às carreiras militares, o que de uma forma ou de outra vai Ihe exigir um certo conhecimento acadêmico. Todavia, há muita distância entre o falar e o fazer. Tanto na prática docente como discente, da grande maioria, os fatos citados não se configuram. Em realidade, o professor "dá" o conteúdo, a aplicabilidade fica na retórica e, o aluno prefere as vantagens de um ensino facilitado.

Sobre a dificuldade e facilidade do noturno, as contradições foram várias e nos dois grupos: professores que não quiseram se manifestar; a cultura institucional de que no noturno tudo é mais facilitado; a falta de base e tempo como justificativas e o hábito da prova como único instrumento de avaliação. Os componentes curriculares mais difíceis, tanto para professores (64\% não se pronunciaram) como para os alunos, são as exatas: Matemática, Física e Química. A estas os alunos acrescentaram: Inglês Língua Portuguesa, Geografia, Biologia, Arte, História e Filosofia. Os componentes curriculares mais fáceis destacados pelos alunos foram: História, Língua Portuguesa, Matemática, Biologia, Geografia, Inglês, Filosofia, Química, Arte e Sociologia. 76\% dos professores não se pronunciaram.

Queremos aqui ressaltar que a dificuldade nas disciplinas exatas é conseqüência da falta de base cognitiva, do saber que deveria ser construído ao longo dos anos de escolaridade, mas que não foi.
Quando muito, foi colado ou decorado para a prova e, esquecido. Outrossim, é a contradição observada, pois, os mesmos componentes curriculares citados também como difíceis, igualmente são destacados como fáceis, tais como: Inglês Língua Portuguesa, História, Matemática, Biologia, Geografia, Filosofia e Arte. Concordamos com a opinião de alguns professores de que esta facilidade/dificuldade refere-se aos modelos de avaliação sofridos pelo aluno.

Reafirmando este raciocínio, percebemos que tanto na justificativa da dificuldade quanto da facilidade aparece o sentimento do não gostar/gostar do professor. $\bigcirc$ gostar se traduz na forma como o professor "dá" a sua aula, e o não gostar, no desinteresse docente em proporcionar aulas mais dinâmicas, além das faltas (que não são poucas), o que ocasiona a desmotivação dos alunos. Apesar da falta de base acadêmica e da falta de tempo para estudar assumidos pela maioria dos respondentes, é a figura mágica do professor o grande diferencial para o aluno aprender.

Considerando-se as dificuldades do aluno do curso noturno, solicitamos a opinião de professores e alunos sobre a necessidade da reestruturação do ensino noturno, visando a um ensino de melhor qualidade, 60\% dos docentes e $61 \%$ dos discentes consideraram que são favoráveis em parte, pois a decisão deve ter um espaço maior de discussão, devido à importância e aos aspectos complexos que a envolvem.

A respeito das razões que levam um(a) aluno(a) a abandonar o curso, $44 \%$ dos professores e $40 \%$ dos alunos concordam que no Kennedy, a que mais acontece é quando ele consegue um emprego e fica 
sem horário para estudar. Uma vez mais chamamos a atenção para a realidade social do ensino noturno: 1) Fato - são muito altos os índices de evasão (desistência) e de repetência dos jovens que estudam à noite. 2) Causa - esses jovens são oriundos de classes populares, só se escolarizam se puderem estudar à noite e trabalhar de dia, portanto, eles não têm tempo, nem o hábito de estudar. Chegam ao ensino médio sem o conteúdo básico, onde o sistema de dependência maquiou o problema, não o solucionou. 3) Conseqüência: elitizar cada vez mais o ensino, deixando como única oportunidade escolar para esses jovens o Curso Supletivo e afins.

Considerando a realidade, os interesses pessoais e profissionais, os sonhos e ideais dos atores, não querendo com isso oferecer um curso de menor qualidade, mas sim um ensino mais adequado à realidade, às necessidades e aos interesses da clientela do Kennedy, professores e alunos deram a sua opinião sobre as mudanças possíveis e viáveis. As duas opções mais votadas entre os professores foram: mudanças na parte diversificada do currículo, com a possibilidade de acontecer aos sábados e ser oferecido sob a forma de oficinas de esporte, informática, paisagismo, reciclagem, dança, teatro, artesanato, redação, poesia, música, dentre outros e o ensino por módulos, como é feito no Curso Técnico de Contabilidade. Para os alunos, as mais votadas foram: a eliminação de disciplinas desnecessárias ao curso, sendo lnglês e Arte os componentes mais citados e o ensino por módulos, como já acontece nos cursos técnicos. Neste ponto, professores e alunos concordam que a saída para novos rumos do ensino médio noturno seja o ensino por módulos, experiência bem sucedida nos cursos técnicos das escolas estaduais; e discordam quando os alunos pedem a eliminação de disciplinas. Observamos que não se trata da eliminação deste ou daquele componente, mas na maneira como estes componentes estão sendo trabalhados. É pura questão de metodologia docente.

A respeito dos grandes problemas pedagógicos do curso noturno do Kennedy os professores destacaram: os alunos originários do Ensino Supletivo e do EJA - Ensino de Jovens e Adultos que chegam ao Ensino Médio sem nenhuma condição de desenvolvimento, e como não têm freqüência regular às aulas, as deficiências de conteúdo não são superadas; bem como a permanência de alunos com um mínimo de disciplina, respeito, vontade de mudar, dedicação mínima aos estudos, responsabilidade com a própria aprendizagem e conscientização. Em nono e último lugar aparece a opção sobre a falta de preparo docente para lidar com o tipo de clientela do curso noturno. E quanto aos problemas administrativos $36 \%$ dos professores apontaram os recursos humanos, porque são em quantidade e qualidade deficitários e $32 \%$ as políticas educacionais descontínuas e inoperantes.

Finalizando, na opinião dos professores o maior responsável pelos baixos índices de produtividade dos alunos do curso noturno é o desinteresse e a falta de comprometimento dos próprios alunos.

\section{Novos rumos:}

\section{como e por quê?}

Analisando o cenário da educação nacional, podemos afirmar que pesa sobre o ensino médio as causas da expansão sem qualidade do ensino superior, os descaminhos da educação profissional, a falta de qualifi- 
cação do trabalhador brasileiro e a exclusão de jovens carentes. Esta modalidade de ensino permanece indefinida, apesar das reformas implementadas pelos governos. Mesmo agora quando o Ministério da Educação desenvolve estudos para unificar o ensino médio e a educação profissional, o ensino médio continua um enigma a ser decifrado. Afinal, qual é a sua finalidade?

Entendemos que a última etapa da educação básica - o ensino médio - deve ter por finalidade desenvolver integralmente os alunos, assegurando-Ihes a aquisição de conhecimentos, competências, habilidades e atitudes indispensáveis para o progresso no trabalho, para exercer a cidadania e para continuar os estudos em nível posterior. Ninguém duvida do papel da educação para o fortalecimento da cidadania, o ajustamento dos jovens e sua preparação profissional. No entanto, da maneira como é tratada, a educação não configura uma prioridade política.

A pesquisa no ensino médio nos levou a algumas conclusões, dentre elas a certeza de que é tempo de aprender com os insucessos e nós professores precisamos estudar uma fórmula que faça o ensino médio (principalmente o noturno) deixar de ser problema para se converter em solução.

No CEPK, o ensino médio noturno nos revelou que no corpo discente existem baixos índices de produtividade, altos índices de desistência e freqüência (bastante) irregular às aulas. Alunos que, na sua grande maioria, chegam ao ensino médio totalmente sem condições de prosseguimento de estudos, dificultando a consolidação e o aprofundamento de conhecimentos, que não foram adquiridos no ensino fundamen- tal, principalmente de Língua Portuguesa (leitura, interpretação e redação) e Matemática (quatro operações). Alunos que sofrem com o atual sistema de dependência, pois, não trouxe soluções e, a oportunidade que oferece é irreal, considerando que esta progressão parcial vai exigir muito mais do aluno, uma vez que ele deverá ser aprovado em um número ainda maior de disciplinas. Sendo assim, o ensino noturno não pode ser oferecido de forma idêntica ao diurno, porque as características do aluno são completamente diferentes.

Sobre o corpo docente é possível perceber uma certa dissonância, um abismo entre o discurso e a prática docentes. Entre as declarações de intenções e as verdadeiras realizações. A contradição está visível a olhos nus, é o que emerge e, portanto, o que mais incomoda às equipes pedagógica e administrativa.

Dificilmente um professor assume que possui uma prática educativa autoritária, principalmente na avaliação, porém ela acontece das mais diferentes formas e, que apesar de apregoar a necessidade do pensamento crítico, a grande maioria dos professores não sabe o que é pensamento crítico e, por isso, reproduz o sistema, propicia a formação de cidadãos passivos e de trabalhadores obedientes. Em alguns casos, percebemos até uma certa alienação, quando professores não têm consciência da distinção entre o que deseja, acredita, sente, diz e o que de fato faz. Tudo isso exige profunda reflexão, logo um ótimo ponto de partida para a interação a que nos propomos.

Para tomar consciência da contradição entre o desejo expresso no sonho idealizado dos profissionais da educação e a realidade confusa do ensino médio noturno, é preciso estudar os desdobramentos práti- 
cos do novo paradigma confrontando o que está em vigor com as inovações pretendidas. Estudar o que, o porquê, o como e quando deve ser feito. Analisar as reais possibilidades entre a situação atual e a situação esperada. Levantar os riscos, os beneficiários, as estratégias de implementação. Definir metas. Buscar parcerias. Negociar ações. A maior dificuldade localiza-se, justamente aí, pois os hábitos incorporados dificultam a percepção, por parte dos docentes, de que qualquer mudança visando à inovação necessita de muito estudo para que a solução do problema aconteça. Ocorre que observamos uma certa falta de comprometimento com a mudança, sobretudo com a inovação.

Porém, apesar das contradições percebidas, um ponto é de vital importância, professores e alunos destacaram a credibilidade na escola. Há no Kennedy um clima de mudança. $\bigcirc$ que antes era descrédito e desrespeito, hoje, com a autonomia institucionalizada pela LDB - Lei $n^{\circ}$ 9394/96 (BRASIL, 1996) e regulamentada pelos: Decreto n 2208/97 (BRASIL, 1997), Resolução CNE/ CEB n ${ }^{\circ}$ 04/99 (CONSELHO NACIONAL DE EDUCAÇÃO, 1999) e Parecer CNE/CEB n 17/97 (CONSELHO NACIONAL DE EDUCAÇÃO, 1997), a direção pôde desenvolver uma gestão dinâmica, participativa, democrática, audaciosa, empreendedora e inovadora. A gestão do Kennedy acredita que esta autonomia não é apenas para fins administrativos e financeiros, mas, sobretudo para fins pedagógicos.

Acontece que não basta haver um clima de mudança. Não basta a vontade do grupo de gestores. Não buscamos a mera alteração do comportamento docente, mas algo muito maior que é a mudança de ati- tude da comunidade escolar, o que significa a ampliação do grau de consciência tanto dos professores como dos alunos. $O$ ensino médio noturno não deve ser oferecido de forma idêntica ao diurno, nem tão pouco se configurar num simulacro e, para tal, professores e alunos deverão construir um aprendizado coletivo. Trata-se de inovação. Até porque se pode mudar sem inovar em absolutamente nada.

Para muitos docentes, o mais difícil parece ser vislumbrar "o que" fazer. Há uma certa necessidade de "receitas prontas" seja da equipe técnico-pedagógica da escola, seja da Secretaria de Educação. Reclamou-se tanto das ações que vinham de cima para baixo e, agora, que as ações devem partir de baixo para cima elas não se concretizam. E não se trata apenas da falta de tempo docente, pior, o professor não sabe como inovar!

Precisamos de ação para mudar a realidade, mas não é qualquer tipo de mudança. Buscamos a prática docente consciente e voluntária, de caráter transformador. E aí, queremos pontuar a construção coletiva dos saberes docentes, independente do "foi-a-direção-que-pediu" e, muito diferente do "glacê" de teorias importadas, sem nenhuma adaptação à realidade sociocultural de nossas escolas. Não vai resolver adotar práticas super sofisticadas, que acabam descaracterizadas em função da não-mudança das concepções enraizadas pelos docentes. Trata-se de uma desconstrução e uma reconstrução, partindo do que o professor tem de história pessoal e profissional, saindo do estágio de pré-capacitação até chegar ao estágio da transformação, isto é, promover o desenvolvimento profissional do professor. 
Um primeiro passo já foi dado pela própria Secretaria de Estado de Educação, que veio de encontro às reivindicações de professores: o curso noturno, a partir de fevereiro de 2004, deve oferecer 25 horas/aulas presenciais, aulas de 50 minutos e mais duas aulas de atividades não presenciais, o que decretou o fim das aulas de $40 \mathrm{mi}$ nutos. Ao que parece, este fato não resolveu o problema e acarretou outro, pois o aluno não consegue chegar à escola às 18 horas e, sair às 22:30 h em locais onde campeia a violência, é muito perigoso. Todavia, é hora da comunidade escolar decidir sobre a que e quem o ensino médio noturno se destina? $\bigcirc$ modelo imposto é válido ou que modificações devem ser introduzidas para que esta modalidade de ensino efetivamente funcione?

Com base nos passos da LDB/96 na direção da autonomia da escola, acreditamos que cabe à comunidade escolar do CEPK definir que ênfase será oferecida aos alunos do noturno: ou prioriza-se a transmissão de conhecimentos sistematizados, compartimentados e elencados pelo domínio da "sociedade do conhecimento" (livro didático, vestibular, concursos), o qual a maioria absoluta dos professores acomodou-se; ou produz-se a construção ativa e efetiva de conhecimentos focados no desenvolvimento do aluno direcionados para o mundo do trabaIho - em outras palavras: condições de empregabilidade. Esta definição constará do Projeto Pedagógico e, para realizála é preciso que a comunidade participe ativamente da elaboração do projeto, como também defenda aquilo que ela (comunidade) acredita ser fundamental para sair da Pedagogia do Fracasso para a Pedagogia do Sucesso.
Nossa análise é que o modelo imposto de uniformização do ensino médio penaliza todos os alunos. Uma vez que a dinâmica das aulas deve atender ao nível de conhecimento da grande maioria, os alunos que tiveram a sorte de ter freqüentado um bom ensino fundamental, são prejudicados em função dos colegas que não tiveram tal sorte. $E$ os alunos oriundos de outras modalidades de ensino (Educação de Jovens e Adultos - EJA, Centro de Estudo Supletivo - CES), também são prejudicados, pois apesar dos esforços docentes e deles próprios, eles apresentam baixo rendimento, porque as lacunas de conteúdo são muito grandes. São prejudicados aqueles que não têm pretensões acadêmicas, porque não são preparados para a competitividade do mercado de trabalho, como também os que sonham com o ensino superior, pois não possuem conhecimento básico para permanecerem no mundo acadêmico. $\bigcirc$ resultado nós encontramos: evasão e repetência.

Os Parâmetros Curriculares Nacionais (1998), atendendo a LDB/96, propõem às escolas um currículo voltado para as necessidades básicas do indivíduo, como formação em sua totalidade e preparação para o exercício do trabalho. Entendemos que o trabalho faz parte da vida, mas a formação do indivíduo não se reduz apenas ao mercado de trabalho. Educar para a vida é levar o aluno a perceber-se como sujeito de suas ações, um ser ativo, apto a intervir na realidade na qual vive e convive. Pelas razões expostas, sugerimos que a escola deva dispor da autonomia garantida por dispositivos legais para se adequar ao seu público e que a comunidade escolar, com acompanhamento pedagógico, decida sobre a reestruturação curricular possível e viável, fa- 
zendo com que os alunos cumpram os componentes da base nacional com tempo diferente e um tratamento adequado, possibilitando não apenas um certificado, mas a apreensão do conhecimento. Esta fórmula não está pronta, ela precisa ser construída pela comunidade escolar.

Pelos aspectos pontuados pela pesquisa, acreditamos que o CEPK tem autonomia para diversificar a proposta curricular do ensino médio noturno. A decisão curricular tem que atender a uma organização de conhecimento. Neste contexto, aulas de Física só têm razão de ser, depois que o aluno domine a Matemática. Portanto, o currículo precisa ser reformulado, ter seu caráter acadêmico reduzido e incluir conteúdos não hierarquizados, porém significativos para os alunos e relacionados aos seus saberes e às expectativas do cotidiano. $\bigcirc$ currículo faz a diferença.

Reiteramos a necessidade de professores e alunos estudarem e decidirem sobre que conhecimentos favorecem o sucesso escolar e, simultaneamente, a preparação básica para o mundo do trabalho. Cabe ao professor assumir uma nova postura, não de denunciar o que não está dando certo, mas de conhecer a clientela com que trabalha e organizar uma prática pedagógica com e sobre os saberes dessa clientela. Denunciar, assumindo uma postura teórica, sem conhecer profundamente que mudanças ocorreram, cai também no vazio da simples denúncia. Cabe aos dirigentes escolares captar do professor como ele realiza o seu fazer pedagógico e levá-lo a perceber como usava e usa esse saber nas suas próprias práticas pedagógicas e na elaboração de novas práticas realizadas no cotidiano da sala de aula. É uma tentativa de fazer o professor pensar criticamente sobre suas ações, possibilitando-o condições concretas, reais e viáveis de ensino-aprendizagem. Como as mudanças em educação são muito lentas, pouco a pouco o professor se percebe como sujeito do seu fazer pedagógico, aprendendo novos conhecimentos que ainda não tinha, mas que passa a sentir que precisa ter para ser o conceptor e executor da sua própria pratica pedagógica.

Sem nenhuma sombra de dúvidas, acreditamos que a grande melhoria na educação secundária só ocorrerá de fato, quando o ensino fundamental cumprir seus propósitos, que é o de ensinar a ler, escrever e contar. Contudo, uma melhoria relativa é possível, se o foco dos currículos recair sobre as necessidades dos alunos do ensino médio noturno.

Muita coisa precisa mudar na educação, inclusive as políticas públicas, nesta medida, culpar apenas o professor por tudo que acontece de ruim da educação, a contradição deixa de ser um elemento de crescimento e torna-se uma forma sutil de anular a capacidade de ação docente. TrabaIhar com as contradições nem sempre é fácil ou tranqüilo, pelo contrário - é conflitante. É no seu enfrentamento que se manifestam: fraquezas, pontos vulneráveis, aqueles onde a convicção não está fortalecida. Assumir a contradição é decisivo, pois implica a existência de um trabalho a ser feito. Educação não é sinônimo de consenso.

Nesta finalização, queremos agradecer o apoio recebido pela direção e pelo conselho pedagógico do C.E. Presidente Kennedy e, reafirmar que a mudança-inovação é um comprometimento de todos - é a comunidade escolar estudando e pesquisando, aprendendo a fazer ações e práticas pedagógicas efetivas, eficientes e efi- 
cazes; ações e práticas que possam proporcionar rumos de sucesso aos alunos e professores do curso noturno.

Afinal, considerando a afirmativa de Peter Drucker (2001, p. 165) - "a escola é res- ponsável pelos resultados que produz" - até quando vamos permitir que o ensino médio noturno seja uma mentira? Um ensino médio que foi criado para alunos idealizados, que concluíram com sucesso um excelente ensino fundamental que nuca existiu.

\section{Referências}

BRASIL. Decreto n. 2.208, de 17 de abril de 1997. Regulamenta o $\S 2^{\circ}$. Do art. 36 e os arts. 39 e 42 da Lei $n^{\circ}$. 9.394, de 20 de dezembro de 1996, que estabelece as diretrizes e bases da educação nacional. Pedagogia em Foco, [S. I. ] , 1997? Disponível em:

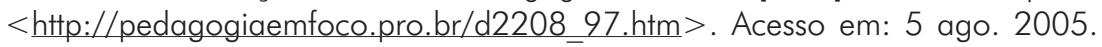

. Lei n.9.394, de 20 de dezembro de 1996. Estabelece as diretrizes e bases da educação nacional. Legislação, Brasília, DF, 1996. Disponível em: < http:// www.mec.gov.br/sef/fundef/Ftp/lein9394.doc.>. Acesso em: 5 ago. 2005.

CARVAlHO, C. P. Ensino noturno: realidade e ilusão. 5. ed. São Paulo: Cortez, 1986.

CONSELHO NACIONAL DE EDUCAÇÃO (Brasil).Câmara de Educação Básica. Parecer CNE/CEB n. 17, de 3 de dezembro de 1997. Diretrizes operacionais para a educação profissional, em nível nacional. Atos normativos, Brasília, DF, 1997. Disponível em: < http://portal.mec.gov.Br/cne/index. >. Acesso em: 5 ago. 2005.

CONSELHO NACIONAL DE EDUCAÇÃO (Brasil).Câmara de Educação Básica. Resolução CNE/CEB n. 4, de 8 de novembro de 1999. Institui as diretrizes curriculares nacionais para a educação profissional de nível técnico. Atos normativos, Brasília, DF, 1999. Disponível em: < http://portal.mec.gov.Br/cne/index.>. Acesso em: 5 ago. 2005.

DELORS, J. et al. (Coord.). Educação: um tesouro a descobrir: relatório para UNESCO da Comissão Internacional sobre Educação para o século XXI. 2. ed. São Paulo: Cortez; Brasília, DF: UNESCO, 1999.

DRUCKER, P. F. O melhor de Peter Drucker: a sociedade. Sâo Paulo: Nobel, 2001.

GIMENO SACRISTÁN, J. O currículo: uma reflexão sobre a prática. 3. ed. Porto Alegre: Artmed, 2000.

KUENZER, A. Ensino de $2^{\circ}$ grau: o trabalho como princípio educativo. São Paulo:

Cortez, 1988. 
PACHECO, J. A. Políticas curriculares: referenciais para análise. Porto Alegre, RS: Artmed, 2003.

PARÂMETROS Curriculares Nacionais. Brasília, DF: MEC, Secretaria de Educação Fundamental, 1998.

PERRENOUD, P. Pedagogia diferenciada: das intenções à ação. Porto Alegre: Artmed, 2000.

A pedagogia na escola das diferenças: fragmentos de uma sociologia do fracasso. 2. ed. Porto Alegre: Artmed, 2001.

REVISTA DO ENSINO MÉDIO. Brasília, DF: MEC, Secretaria de Educação Média e Tecnológica, ano 1, n. 1, jun./jul. 2003.

RODRIGUES, L. Da prática a teoria: uma experiência em educação básica. 1987. Tese (Doutorado em Educação)-Universidad Faculdad de Ciências de la Educación, Universidad Autônoma de Barcelona, Barcelona, 1987.

SCHÖN, D. A. Educando o profissional reflexivo: um design para o ensino e a aprendizagem. Porto Alegre, RS: Artmed, 2000.

TEVES, N. (Org.). Imaginário social e educação. Rio Janeiro: Gryphus, 1992.

VASCONCELLOS, C. S. Para onde vai o professor?: resgate do professor como sujeito de transformação. 9. ed. São Paulo: Libertad, 2001.

YIN, R. K. Estudo de caso: planejamento e métodos. 2. ed. Porto Alegre: Bookman, 2001.

Recebido em: 17/08/2004

Aceito para publicação em: 22/02/2005 